\title{
The 2021 European Training Requirements in Paediatric Endocrinology and Diabetes
}

\author{
Kanetee Busiah ${ }^{\mathrm{a}} \quad$ Aleksandr Peet $^{\mathrm{b}} \quad$ Gianluca Tornese $^{\mathrm{c}} \quad$ Naomi Weintrob $^{\mathrm{d}} \mathrm{e}$ \\ John Schulga ${ }^{f}$ Rasha T. Hamza $^{g}$ Berthold Koletzko ${ }^{\text {h, } i}$ Rob Ross Russell ${ }^{j}$ \\ Arthur Felicek $^{k}$ Leena Patel, m \\ aPaediatric Endocrinology, Diabetology and Obesity Unit, Lausanne University Hospital, Lausanne University, \\ Lausanne, Switzerland; b Children's Clinic of Tartu University Hospital, Institute of Clinical Medicine, Faculty of \\ Medicine, Tartu University, Tartu, Estonia; 'Institute for Maternal and Child Health IRCCS "Burlo Garofolo", Trieste,

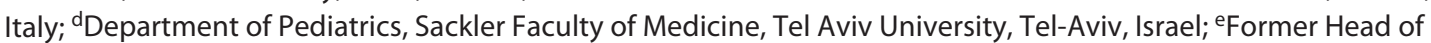 \\ Pediatric Endocrinology and Diabetes Unit, Dana-Dwek Children's Hospital, Tel-Aviv Medical Center, Tel-Aviv, Israel; \\ ${ }^{f}$ Consultant Paediatrician, NHS Forth Valley Women \& Children Department, Forth Valley Royal Hospital, Larbert, UK; \\ פDepartment of Pediatrics, Pediatric Endocrinology Unit, Faculty of Medicine, Ain Shams University, Cairo, Egypt; \\ hEAP Chair of Secondary-Tertiary Care Committee, Else Kröner Senior Professor of Paediatrics, LMU - Ludwig- \\ Maximilians-Universität, Munich, Germany; 'Department of Paediatrics, Dr. von Hauner Children's Hospital, \\ LMU University Hospitals, Munich, Germany; 'EAP Chair of European Board of Paediatrics, Consultant in Paediatric \\ Intensive Care and Respiratory Paediatrics, Addenbrooke's Hospital, Cambridge, UK; kPresident of the European \\ Board of Surgery, President of the UEMS Division of General Surgery, UEMS ETR Committee Reviewer, Professor, \\ Department of Surgery, University of Malta, Msida, Malta; 'Department of Paediatric Endocrinology, Royal \\ Manchester Children's Hospital, Manchester, UK; 'mivision of Medical Education, The University of Manchester, \\ Manchester, UK
}

\section{Keywords}

Curriculum · Syllabus · Tertiary care · Subspeciality training · European Training Requirements · Paediatric endocrinology and diabetes

\begin{abstract}
The aims of the 2021 European Training Requirements (ETR) in Paediatric Endocrinology and Diabetes (PED) are to (1) provide standards to harmonize training programmes in PED between different European countries, (2) establish clearly defined standards of knowledge and skills required to practice PED at the tertiary care level, (3) foster the development of a network of competent tertiary care centres for PED in Europe and globally, and (4) improve the quality of care for children and adolescents requiring PED services. This ETR in PED specifies the requirements for training institutions,
\end{abstract}

trainers, and trainees. It also provides the detailed syllabus/ core content that trainees are expected to achieve in order to become competent independent clinicians in PED. References to consensus guidelines produced and/or endorsed by ESPE are included. The target users are trainees in PED, trainers, and all involved with quality assurance and accreditation. The process to develop and approve this 2021 ETR has been rigorous and involved trainees and consultants in paediatric and adult Endocrinology, ESPE (Syllabus Task Force, Education and Training Committee, Council), European Academy of Paediatrics (Tertiary Care Council, Assembly), European Board of Paediatrics, and Union of European Medical Specialists. Implementing the ETR will complement professional regulatory requirements for postgraduate training

Rasha T. Hamza contributed on behalf of members of ESPE Education and Training Committee. karger@karger.com www.karger.com/hrp

Karger $\stackrel{\text { ' }}{=}$

BOPEN ACCESS
(C) 2021 The Author(s)

Published by S. Karger AG, Basel

This is an Open Access article licensed under the Creative Common Attribution-NonCommercial-4.0 International License (CC BY-NC) (http://www.karger.com/Services/OpenAccessLicense), applicable to the online version of the article only. Usage and distribution for commercial purposes requires written permission.
Correspondence to:

Kanetee Busiah, kanetee.busiah@chuv.ch 
in PED in different countries and allow harmonizing standards across Europe. ETR is publicly available at www. eurospe.org/education/education-training-syllabus and at https://www.uems.eu/_data/assets/pdf_file/0007/ 133990/UEMS-2021.17-European-Training-Requirement-inPaediatric-Endocrinology.pdf. @ 2021 The Author(s).

\section{Introduction}

This study presents the rationale that underpins the European standards for training in medical (sub)specialities, the roles of various organisations involved in developing the 2021 European Training Requirements (ETR) in Paediatric Endocrinology and Diabetes (PED), and an overview of what it comprises [1]. ETR is publicly available at www.eurospe.org/education/educationtraining-syllabus and at https://www.uems.eu/_data/assets/pdf_file/0007/133990/UEMS-2021.17-EuropeanTraining-Requirement-in-Paediatric-Endocrinology. pdf. The 2021 ETR in PED aims to (1) provide standards to harmonize training programmes in PED between different European countries, (2) establish clearly defined standards of knowledge and skills required to practice PED at the tertiary care level, (3) foster the development of a network of competent centres for PED in Europe and globally, and (4) improve the quality of care for children and adolescents requiring PED services.

\section{Rationale for European Training Requirements and Roles of Various Organisations}

\section{Union Européenne Des Médecins Spécialistes/Union}

of European Medical Specialists (UEMS)

UEMS is a non-governmental organisation representing national associations of medical specialists from member countries of the European Union and specialist sections of European Boards [2]. UEMS aims to ensure high standards for training across Europe. These standards are intended to complement the training standards in individual countries and to pave the way to improve the quality of care for all citizens.

The European Commission Directive 2005/36/EC legally enables automatic mutual recognition of medical qualifications and free movement within all European member states on the basis of harmonized minimum training requirements [3]. UEMS has set out the minimum requirements for training in the ETR for each dis- cipline. Each ETR specifies the standards for curricula which includes syllabus (i.e., content) and the practical (process and practice for instructional methods and assessments) and productive (outcomes) aspects that are planned, purposeful, systematic, and progressive.

\section{European Academy of Paediatrics (EAP) and}

European Board of Paediatrics (EBP)

The EAP is a not-for-profit and non-governmental association that aims to improve standards in training, service, and research and to represent the professional interests of paediatricians in Europe [4]. EAP's Secondary/ Tertiary Care Council includes representatives from paediatric subspecialities, such as ESPEs "Accreditation and Syllabus Convener." The latter is a member of ESPE's Education and Training Committee.

EBP is the Executive of the Paediatric Section of UEMS [5]. Its key role is to maintain the highest possible standards of training in paediatrics across Europe, and the primary output is therefore ETRs. The EBP sits within the EAP and thus provides the link between EAP and UEMS (Fig. 1).

The ETRs are developed jointly between the EAP, EBP, and European specialist societies. They are voted on at a General Assembly meeting of the EBP and then submitted to a council meeting of the UEMS for official approval. Together, EAP and the subspecialities are responsible for maintaining the ETR documents.

\section{Subspeciality Training Requirements in Paediatric Endocrinology and Diabetes in Europe since the 1990s}

Regular updates that reflect scientific and medical progress are recommended for the ETR and at approximately 5 -year intervals. The first comprehensive training syllabus in PED was developed in 1995 and was last revised in 2014 [6-8].

The 2021 ETR in PED was initially prepared by ESPE's Syllabus Taskforce on behalf of the Education and Training Committee. Contributions were obtained from paediatric and adult trainees and specialists in endocrinology and diabetes representing countries within Europe and beyond. Thereafter, the Chair and members of the Education and Training Committee and members of the ESPE council in 2020, EAP's Secondary/Tertiary Care Council in 2020-21, and UEMS in 2021 peer-reviewed the ETR. Finalized ETR was approved by the Tertiary Care Council and General Assembly of the EAP and the EBP in January 2021 and ratified by UEMS in April 2021. The process used to develop the ETR strengthens the validity of the recommendations. 


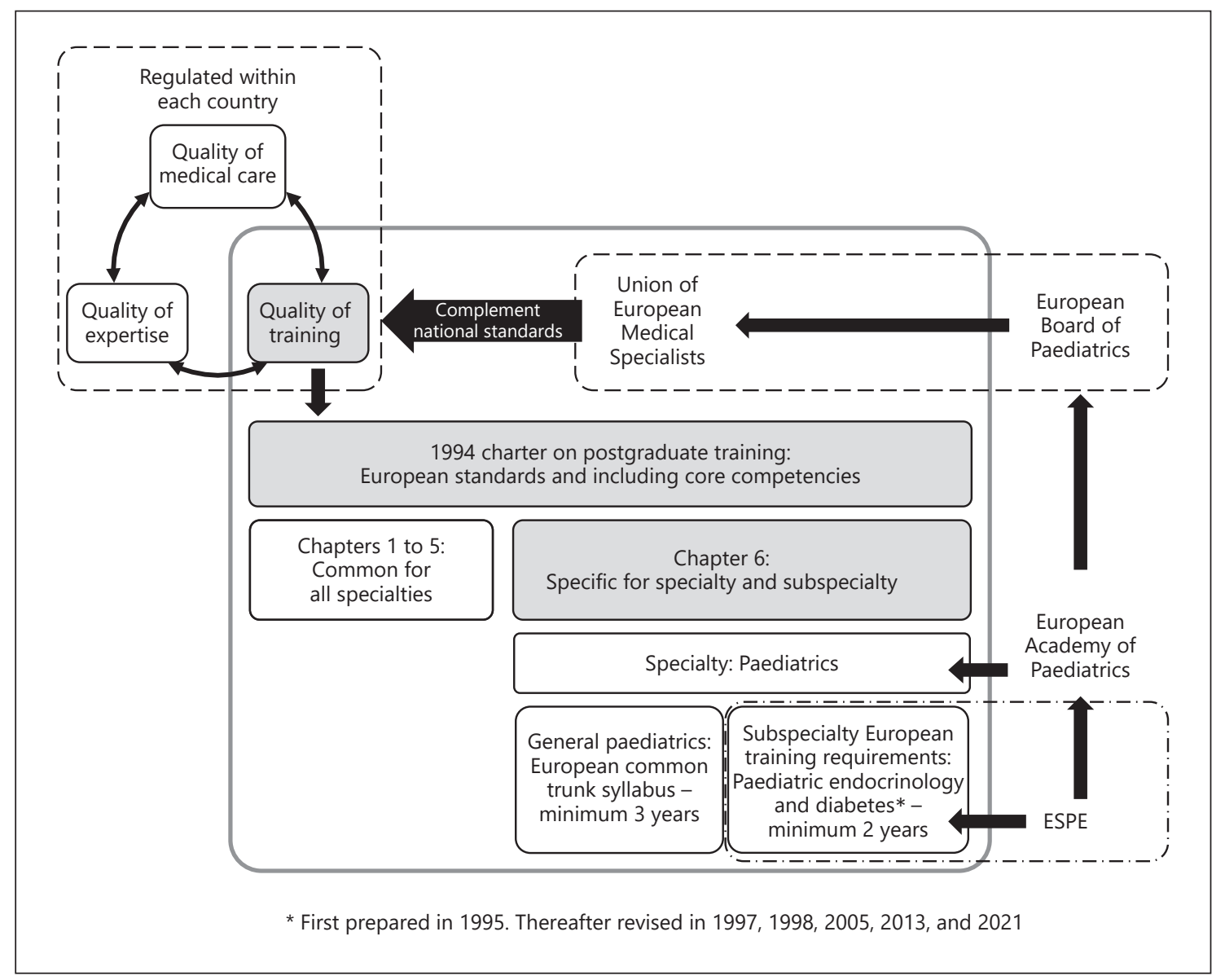

Fig. 1. The roles of Union Européenne des Médecins Spécialistes/Union of European Medical Specialists, European Board of Paediatrics, European Academy of Paediatrics, and ESPE for the development of the European Training Requirements in Paediatric Endocrinology and Diabetes.

\section{Summary of Contents of the 2021 European Training Requirements in Paediatric Endocrinology and Diabetes}

The aim of tertiary care training in PED is to equip clinicians with the competencies required to provide safe high-quality care for children and adolescents who present with common as well as rare endocrine problems. By the end of training, the subspecialist is expected to display the characteristics and competencies for each of the 7 roles described by the CanMEDS framework [9] that are Medical expert, Communicator, Collaborator, Leader, Health advocate, Scholar and researcher, and Professional plus the additional role of mentor. To facilitate achieving these, the ETR in PED specifies the requirements for the following: training period, research training, training institutions, trainers, and trainees. It also provides details for a range of nontechnical skills (Fig. 2) and the subspeciality syllabus/core content.

Each item in the subspeciality syllabus is categorized as $\mathrm{B}$ for basic knowledge; $\mathrm{C}$ for core and essential clinical knowledge, skills, and reasoning, for problems that are routinely encountered; and D for desirable clinical knowledge, skills, and reasoning, for problems that are rare and therefore may not be encountered during training (Fig. 2). Trainees are expected to assimilate and integrate these from their training experiences and different modes of learning.

The 5 levels of clinical competence from novice to competent independent clinician defined by UEMS have been adapted for PED for the 7 components which are (1) knowledge base, (2) clinical assessment, (3) management and follow-up, (4) clinical reasoning: diagnostic, clinical judgement, and decision-making skills, (5) clinical communication and team working, (6) medical record keep- 


\begin{tabular}{|c|c|c|c|c|}
\hline \multicolumn{5}{|c|}{ Content - what a trainee needs to learn } \\
\hline $\begin{array}{l}\text { Cross cutting and } \\
\text { non-technical skills }\end{array}$ & \multicolumn{4}{|c|}{ Subspecialty specific syllabus } \\
\hline \multirow{2}{*}{$\begin{array}{l}\text { A. Professionalism (attitudes) } \\
\text { B. Communication } \\
\text { C. Situation awareness } \\
\text { D. Decision making } \\
\text { E. Safeguarding } \\
\text { F. Leadership } \\
\text { G. Team working } \\
\text { H. Time and task } \\
\text { management } \\
\text { I. Health economics and } \\
\text { service provision } \\
\text { J. Science and biostatistics } \\
\text { K. Self-directed learning } \\
\text { L. Generic teaching/ } \\
\text { education skills }\end{array}$} & B. Basic knowledge & \multicolumn{2}{|c|}{$\begin{array}{l}\text { C. Core/essential clinical knowledge, } \\
\text { skills and reasoning, } \\
\text { for problems that are routinely } \\
\text { encountered }\end{array}$} & $\begin{array}{l}\text { D. Desirable clinical } \\
\text { knowledge, skills and } \\
\text { reasoning, for problems } \\
\text { that are rare }\end{array}$ \\
\hline & $\begin{array}{l}\text { A. Biomedical } \\
\text { knowledge } \\
\text { B. Procedural skills } \\
\text { C. Emergencies } \\
\text { D. Growth - } \\
\text { short stature } \\
\text { E. Growth - } \\
\text { tall stature and } \\
\text { overgrowth }\end{array}$ & $\begin{array}{l}\text { F. Puberty } \\
\text { G. Weight disorders } \\
\text { H. Pituitary, } \\
\text { hypothalamus, } \\
\text { central nervous } \\
\text { system } \\
\text { I. Thyroid } \\
\text { J. Parathyroid, } \\
\text { metabolic bone } \\
\text { and mineral } \\
\text { disorders }\end{array}$ & $\begin{array}{l}\text { K. Adrenal glands } \\
\text { L. Sex development, } \\
\text { gender } \\
\text { M. Disorders of testes, } \\
\text { male reproductive } \\
\text { tract } \\
\text { N. Disorders of ovaries, } \\
\text { female reproductive } \\
\text { tract }\end{array}$ & $\begin{array}{l}\text { O. Glucose \& } \\
\text { lipid metabolism } \\
\text { - Diabetes } \\
\text { P. Glucose \& } \\
\text { lipid metabolism } \\
\text { - Hypoglycaemia } \\
\text { Q. Salt \& water regulation } \\
\text { R. Conditions with } \\
\text { endocrine features }\end{array}$ \\
\hline
\end{tabular}

Fig. 2. Content for the European Training Requirements in Paediatric Endocrinology and Diabetes.

Table 1. Competence levels for 7 components of clinical knowledge, skills, and reasoning

\begin{tabular}{llllll}
\hline Level & 1 & 2 & 3 & 4 & 5 \\
\hline Trainee & Has observed & $\begin{array}{l}\text { Can do with } \\
\text { assistance }\end{array}$ & $\begin{array}{l}\text { Can do but may need } \\
\text { assistance }\end{array}$ & $\begin{array}{l}\text { Competent to do without } \\
\text { assistance }\end{array}$ & $\begin{array}{l}\text { Can be "trusted" to do independently and } \\
\text { without assistance or need for advice }\end{array}$ \\
\hline $\begin{array}{l}\text { Extent of supervision } \\
\text { required }\end{array}$ & $\begin{array}{l}\text { Enhanced direct } \\
\text { supervision }\end{array}$ & $\begin{array}{l}\text { Direct } \\
\text { supervision }\end{array}$ & $\begin{array}{l}\text { Indirect supervision } \\
\text { when required }\end{array}$ & $\begin{array}{l}\text { Occasional ad hoc advice } \\
\text { from supervisor }\end{array}$ & $\begin{array}{l}\text { Independent and no supervision required } \\
\text { Can supervise others }\end{array}$ \\
\hline
\end{tabular}

The extent of supervision is specified for each level. Adapted from those defined by UEMS.

ing and written communication, and (7) reflective practice (Table 1). References to consensus guidelines and statements produced and/or endorsed by ESPE and seminal papers relevant for practicing clinicians are included. Continuous monitoring and evaluation, using a range of measures and including workplace-based assessments, will provide information about trainees' progress and contribute to quality assurance.

\section{Use of the 2021 European Training Requirements in Paediatric Endocrinology and Diabetes}

\section{National Level and Training Institutions in Different Countries}

The ETR is intended to complement the standards and regulatory requirements for postgraduate training in PED in each country and not to supersede them. Adopt- ing the standards in the ETR is a prerequisite for centre accreditation. Training institutions and tertiary care centres can use the ETR as a tool for quality assurance and undertake a self-assessment against the standards provided. The standards can also be used by national training authorities and organisations such as ESPE and EBP for accreditation of training centres.

\section{Trainers and Trainees}

The requirements for trainers and trainees are presented in separate sections of the ETR. Each trainee should be actively involved in the care of children and adolescents. They are required to keep a portfolio with an up-to-date logbook of case encounters and evidence of their learning, development, and progress. Formative assessments and using different tools are recommended throughout training [10]. At regular intervals throughout training, they should self-assess their level of competence 


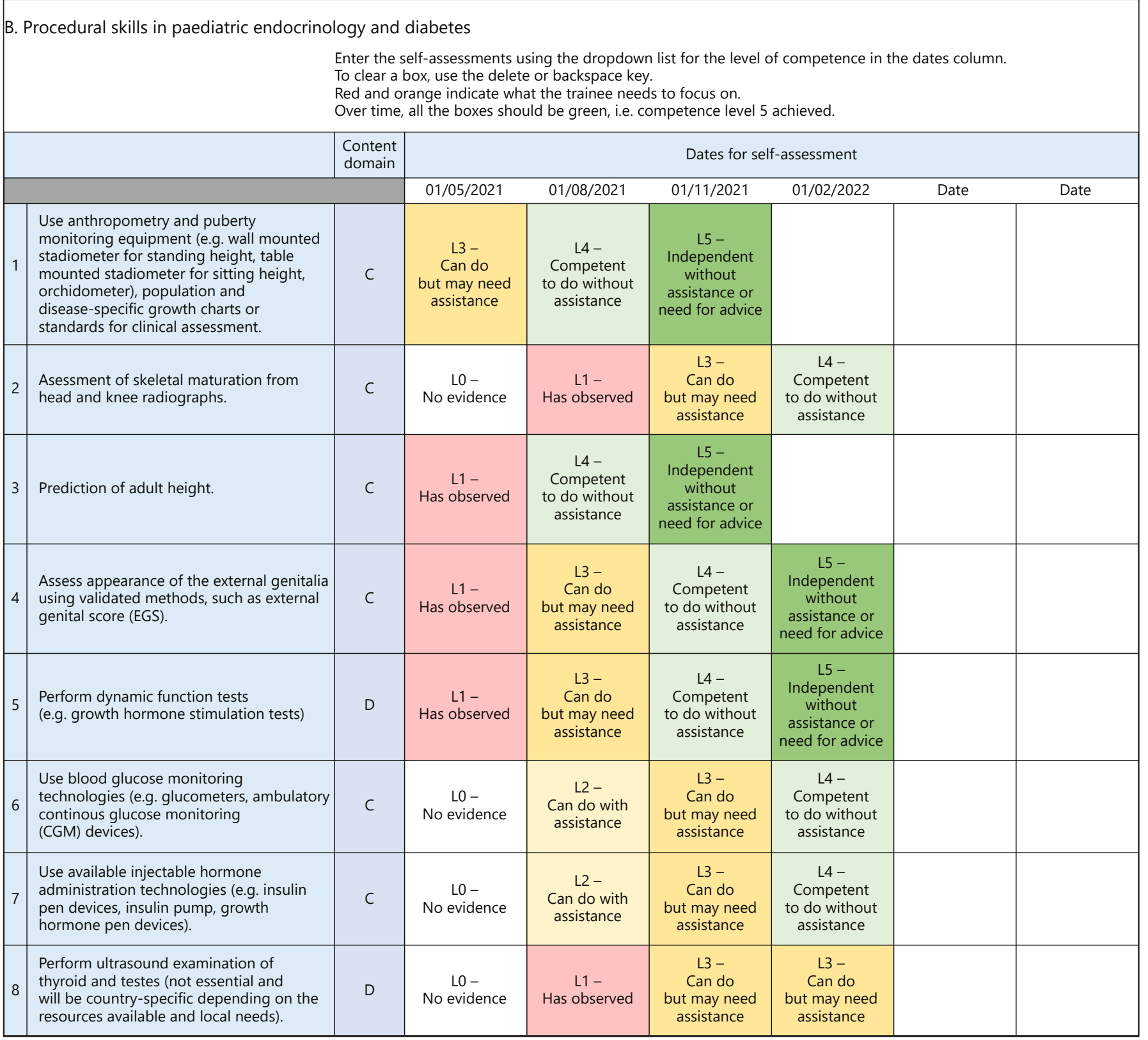

Fig. 3. Example of the section on procedural skills from the Content/Syllabus tracking tool. This illustrates 8 content items, the domain for each item ( $\mathrm{C}$ for common and $\mathrm{D}$ for rare conditions), and how a trainee might complete at 3-month intervals.

for the items in the syllabus and jointly review with their trainer/educational supervisor. To facilitate this, an online PED Content/Syllabus tracking tool is available from the ESPE website (Fig. 3) [1].

\section{Approval and Accreditation}

Further to UEMS recommendations, the EBP initiated a European Training centre Visitation program for ac- creditation of tertiary care paediatric specialities in 2008. It has proposed that the visitation program is arranged jointly with EAP-UEMS, paediatric subspeciality organisations such as ESPE, and national training authorities. An independent process of accreditation of training centres has benefits for centres, trainers, and prospective trainees, by providing objective evidence about the standards of training and formal recognition. 


\section{Conclusion}

This 2021 ETR in PED specifies the up-to-date requirements for training institutions, trainers, and trainees. It also provides the detailed syllabus/core content that trainees are expected to achieve in order to become competent independent clinicians in PED. Implementing the ETR will complement professional regulatory requirements for postgraduate training in PED in different countries. This allows harmonizing standards across Europe and provides a model to use globally.

\section{Acknowledgments}

We are grateful to all listed below who have provided constructive comments and contributed to the 2021 ETR in PED: Trainees: Amish Chinoy, Paediatric Endocrine Research Fellow, Department of Paediatric Endocrinology, Royal Manchester Children's Hospital, United Kingdom. Chris Worth, Paediatric Endocrine Research Fellow, Department of Paediatric Endocrinology, Royal Manchester Children's Hospital, United Kingdom. Maria-Cristina Antoniou, Paediatric Endocrine Trainee, Endocrinology, Diabetology and Obesity unit, Lausanne University Hospital, Lausanne University, Switzerland. María de los Ángeles Gómez Cano, Paediatric Endocrine Trainee, Department of Paediatric Endocrinology, Hospital 12 de Octubre, Madrid, Spain. Patricia Pérez Mohand, Paediatric Endocrine Trainee, Department of Paediatric Endocrinology, Hospital 12 de Octubre, Madrid, Spain. Specialists in paediatric, adolescent and adult endocrinology: Claire Higham, Consultant Endocrinologist, The Christie Hospital, Manchester, UK. Daphne Yau, Consultant Pediatric Endocrinologist, University of Saskatchewan, Canada. Indraneel Banerjee, Consultant Paediatric Endocrinologist, Department of Paediatric Endocrinology, Royal Manchester Children's Hospital, United Kingdom. John Schulga, Consultant Paediatrician and Lead for Paediatric Diabetes \& Endocrinology, NHS Forth Valley; Honorary lecturer, Glasgow University, Scotland. Meghna Chawla, Consultant Paediatric Endocrinologist, Grant Medical Foundation, Ruby Hall Clinic Group of Hospitals, Pune, India. Mya Sandar Thein, Consultant Paediatric Endocrinologist, Yangon Children's Hospital, Myanmar. Philip Murray, Consultant Paediatric Endocrinologist, Department of Paediatric Endocrinology, Royal Manchester Children's Hospital, United Kingdom. Raja Padidela, Consultant Paediatric Endocrinologist, Department of Paediatric Endocrinology, Royal Manchester Children's Hospital, United Kingdom. Members of the ESPE Education and Training Committee (ETC): Rasa Verkauskiene, Chair of ESPE ETC 2016-2019. Professor and Head of Department, Department and Institute of Endocrinology, Lithuanian University of Health Sciences, Kaunas, Lithuania. Abdelhadi Habeb, Consultant Pediatric Endocrinologist, Chairman of Pediatrics, PMBAH, National Guard Ministry, Madinah, Kingdom of Saudi Arabia. Andrea Luczay, ESPE Accreditation and Syllabus Convener 2016-2019. Head of Endocrinology, Department of Paediatrics, Semmelweis University, Budapest, Hungary. Annemieke Boot, Pediatric Endocrinologist, University Medical Center Groningen; Beatrix Children's Hospital, Groningen, the
Netherlands. Francesco Chiarelli, Professor of Paediatrics and Paediatric Endocrinology, Department of Paediatrics, University of Chieti, Chieti, Italy. Ieuan Hughes, Emeritus Professor of Paediatrics, University of Cambridge, United Kingdom. Jan Lebl, Professor and Head, Department of Pediatrics, Charles University in Prague, 2nd Faculty of Medicine, Prague, Czech Republic. Justin Davies, Consultant Paediatric Endocrinologist, Southampton Children's Hospital, Southampton, United Kingdom. Violeta Iotova, Paediatric Endocrinologist, Professor and Head, Clinic of Paediatric Endocrinology, UMHAT "St Marina," Varna, Bulgaria. Members of the ESPE Council: Agnès Linglart, Professor of Paediatrics, Bicêtre Paris Sud Paris Saclay University and Hospital, Paris, France. Evangelia Charmandari, Professor of Pediatric and Adolescent Endocrinology, Division of Endocrinology, Metabolism and Diabetes, First Department of Pediatrics, National and Kapodistrian University of Athens Medical School, "Aghia Sophia" Children's Hospital, Athens, Greece. Syed Faisal Ahmed, Samson Gemmell Chair of Child Health, University of Glasgow, UK. Members of UEMS: Nada Cikes, UEMS Vice President, Enlarged Executive Committee, Rheumatology Section and Board. Professor, Division of Clinical Immunology and Rheumatology, Department of Medicine, University Hospital Centre Zagreb, Croatia. Tibor Ertl, UEMS ETR Review Committee. Emeritus Professor of Pediatrics and Neonatology, University of Pécs, Association of Hungarian Medical Societies.

\section{Statement of Ethics}

An ethics statement was not required for this study type, as no human or animal subject or material was used.

\section{Conflict of Interest Statement}

The authors have no conflicts of interest to declare.

\section{Funding Sources}

No funding was received for this study.

\section{Author Contributions}

K.B. prepared the first draft and all co-authors provided comments which helped finalize the manuscript. L.P. prepared the table and figures.

\section{Data Availability Statement}

There were no research data generated during this publication. ETR is publicly available at https://www.eurospe.org/education/ education-training-syllabus/. 


\section{References}

1 ESPE. Available from: https://www.eurospe. org/education/education-training-syllabus/ Accessed 2021 Jun 11.

2 UEMS. Available from: www.uems.eu Accessed 2021 Jun 11.

3 European Commission. Available from: https: //ec.europa.eu/growth/single-market/ services/free-movement-professionals/qualifications-recognition_en Accessed 2021 Jun 11.

4 European Academy of Paediatrics. Available from: https://www.eapaediatrics.eu/about/ Accessed 2021 Jun 11.
5 European Board of Paediatrics. Available from: https://www.eapaediatrics.eu/aboutebp/ Accessed 2021 Jun 11.

6 Hindmarsh PC. The European training syllabus in paediatric endocrinology and diabetes. Horm Res. 2001;56(5-6):188-204.

7 Darendeliler F. Paediatric endocrine training in the EU. Horm Res Paediatr. 2016;85(6): 428.
8 ESPE position statement for paediatric endocrinology subspecialty. Horm Res Paediatr. 2016;86(1):1-2.

9 Frank JR, Snell L, Sherbino J, editors. CanMEDS 2015 physician competency framework. Ottawa: Royal College of Physicians and Surgeons of Canada; 2015.

10 Chou S, Cole G, McLaughlin K, Lockyer J. CanMEDS evaluation in Canadian postgraduate training programmes: tools used and programme director satisfaction. Med Educ. 2008 Sep;42(9):879-86. 